\title{
Ekstraksi Citra menggunakan Metode GLCM dan KNN untuk Indentifikasi Jenis Anggrek (Orchidaceae)
}

\author{
Danar Putra Pamungkas ${ }^{1}$ \\ ${ }^{1}$ Program Studi Teknik Informatika Universitas Nusantara PGRI Kediri \\ Idanar@unpkediri.ac.id
}

\section{INFORMASI ARTIKEL \\ Sejarah Artikel: \\ Diterima Redaksi:28 Agustus 2019 \\ Revisi Akhir: 01 Oktober 2019 \\ Diterbitkan Online: 4 Oktober 2019}

\begin{tabular}{l} 
KATA KUNCI \\
\hline Anggrek, \\
Ekstraksi, \\
Fitur, \\
GLCM, \\
Orchidaceae \\
KORESPONDENSI \\
\hline
\end{tabular}

No. HP : 085730047483

E-mail : danar@unpkediri.ac.id

\begin{abstract}
A B $\mathbf{S}$ T $\mathbf{R}$ A $\mathbf{C}$ T
Orchidaceae is the Latin name of an orchid that has various shapes, colors and sizes of flowers with unique features. The shape and color of the lips or labellum is a unique orchid that is a differentiator from other plants. In general, the types of orchids have similar colors, textures and flower petals, this causes a person to have difficulty identifying orchid species, especially people who do not know the characteristics of some types of orchids. Therefore the process of identifying orchids needs to be done automatically with a computer system so that it is expected to make it easier to identify the types of orchids. In this study using the GLCM method for feature extraction and KNN method for the process of identifying orchids or orchidaceae. Stages of identification of orchid images are changing the initial size of the image, conversion into gray degrees, median filters, feature extraction of the GLCM method and identification with the KNN method. The success rate of identifying Orchidaceae or orchids reaches $80 \%$ with an average of $77 \%$. K value influences the success rate of identification, the greater the $\mathrm{K}$ value the smaller the accuracy.
\end{abstract}

\section{PENDAHULUAN}

Orchidaceae merupakan nama latin dari bunga anggrek yang memiliki variasi bentuk, warna dan ukuran bunga yang bermacam-macam dengan ciri-ciri unik. Bentuk dan warna bibir atau labellum merupakan keunikan bunga anggrek yang menjadi pembeda dengan tanaman lain.

Bunga anggrek memiliki struktur dasar tiga sepal (kelopak) dan tiga petal (tajuk bunga). Keindahan bunga anggrek menjadikan bunga ini termasuk komoditas holtikultura yang mempunyai nilai ekonomi tinggi, sehingga tidak sedikit yang membudidayakan bunga anggrek. Aranda, Cattleya, Cymbidium, Dendrobium, Oncidium, Phalaenopsis, Renanthera, dan Vanda merupakan jenis-jenis anggrek yang memiliki nilai ekonomi yang tinggi. Dendrobium dan Phalaenopsis memiliki bunga yang menawan, mahkota yang unik, beragam warna dan bentuk yang khas sehingga dua jenis ini yang umum dibudidayakan. Hampir setiap daerah di Indonesia ada tamanaman anggrek yang dibudidayakan. Di Maluku terdapat 10 genus dan 13 spesies anggrek yang dibudidayakan [1]. Meskipun anggrek banyak yang membudidayakan, karena ada ketergantungan dari masyarakat untuk budidaya harus ada pengawasan dari pihak terkait [2].

Untuk membedakan jenis anggrek satu dengan yang lain yaitu dengan melihat warna, tekstur, kelopak bunga anggrek. Dengan mengetahui perbedaan tersebut seseorang dapat mengidentifikasi jenis suatu bunga anggrek. Namun secara umum jenis-jenis bunga anggrek memiliki kemiripan warna, tekstur dan kelopak bunganya, hal ini yang menyebabkan seseorang kesulitan dalam mengidentifikasi jenis bunga anggrek, khususnya orang awam yang belum mengetahui ciri-ciri dari beberapa jenis bunga anggrek. Oleh karena itu proses identifikasi bunga anggrek perlu dilakukan secara otomastis dengan sistem komputer sehingga diharapkan mempermudah dalam identifikasi jenis-jenis bunga anggrek. Proses identifikasi secara otomatis dapat menerapkan teknologi pengolahan citra digital, diharapkan dapat memudahkan setiap orang untuk mengidentifikasi jenis-jenis bunga anggrek. Proses identifikasi bunga anggrek merupakan salah satu bidang pengenalan pola (pattern recognition).

Identifikasi bunga anggrek berdasarkan warna dan bentuk dapat menggunakan metode ekstraksi fitur warna dan bentuk HSV, Prewit dan Learning Vector Quantization (LVQ) untuk proses klasifikasi dapat diperoleh akurasi 
73,33\% [3]. Selain menggunakan metode ekstraksi fitur, identidikasi bunga anggrek juga dapat dilakukan dengan menggunakan metode deteksi tepi. Dengan menggunakan metode deteksi tepi Canny, Sobel akurasi yang diperoleh untuk identifikasi bunga anggrek antara 40,7\% sampai $55,5 \%$, sedangkan dengan metode HSV mencapai akurasi $70 \%$ [4]. Dari dua penelitian tersebut tinggkat keberhasilan identikfikasi bunga anggrek masih belum mencapai $80 \%$ atau lebih. Metode Gray Level Co-occurrence Matrix (GLCM) juga dapat digunakan untuk pengenalan pola citra digital. Metode GLCM dipadukan dengan metode KNearest Neighbour (KNN) mempunyai tingkat keberhasilan mencapai 57,5 \% dalam pengenalan jenis batik [5]. Metode GLCM digunakan oleh Rahmat Robi Waliansyah dalam idintifikasi jenis daun tengkawang, tinggkat kerberhasilan yang diperoleh $87,5 \%$ sampai $100 \%[6]$. Dengan metode GLCM pengenalan jenis buah jeruk mencapai 91,6\% [7]. Akurasi pengenalan wajah dengan menggunakan metode K-NN mencapai 80\% [8]. Dalam proses pengelompokan metode KNN dapat menghasilkan akurasi sebesar 85,15\% [9]. Penggunaan metode $\mathrm{KNN}$ mempunyai tinggkat keberhasilan yang cukup baik untuk proses klasifikasi yaitu mencapai 86,67\% [10].

Berdasarkan penelitian-penelitian sebelumnya metode GLCM dan KNN mempunyai tingkat keberbasilan mencapai lebih dari $80 \%$. Oleh karena itu pada penelitian ini menggunakan metode GLCM untuk ekstraksi fiturnya dan metode KNN untuk proses identifikasi bunga anggrek atau orchidaceae. belum adannya suatu aplikasi berbasis mobile yang menerapkan metode GLCM dan KNN untuk identifikasi bunga anggrek, penelitian ini menerapkan dua metode tersebut dalam aplikasi berbasis mobile. Selain untuk menerapkan metode GLCM dan KNN untuk identifikasi bunga anggrek, penelitin ini juga untuk mengetahui tingkat keberhasilan mengidentifikasi bunga anggrek. Pengukuran tingkat keberhasilan menggunakan metode Zero-one validation. Aplikasi dibangun menggunakan Bahasa pemrograman C\#. Citra yang digunakan adalah bunga anggrek jenis Phalaenopsis. Penelitian yang dilakukan hanya membedakan ciri tekstur bunga anggrek jenis Phalaenopsis dan dendrobium phalaenopsis. Data citra yang digunakan sejumlah 90 gambar, dimana 30 gambar Phalaenopsis, 30 gambar Dendrobium, dan 30 gambar bunga lain untuk pengujianya.

\section{LANDASAN TEORI}

\subsection{Orchidaceae Phalaenopsis}

Phalaenopsis berasal dari kata "Phalaina" yang berarti kumbang kupu-kupu dan kata "Opsis" yang berarti bentuk. Oleh karena itu di beberapa Negara anggrek ini juga dikenal dengan Moth Orchid (Anggrek Kumbang). Pembentukan genus Phalaenopsis dilakukan oleh ilmuwan dunia bernama Carl Blume pada tahun 1825. Phalaenopsis di Indonesia sendiri telah menyebar keseluruh pelosok daerah dan mampu hidup disegala tempat, bewarna cerah dan corak dekoratif, dengan berbagai macam bentuk dan jenis. Phalaenopsis ini juga memiliki berbagai macam jenis, misalnya: Phalaenopsis, Dendrobium, Phalaenopsis Violacea. Di Indonesia, Phalaenopsis ini dikenal dengan sebutan Anggrek bulan, merupakan jenis anggrek asli
Indonesia yang penyebarannya meliputi daerah Sumatera, Jawa, Kalimantan, Sulawesi dan Maluku.

Jenis-jenis bunga anggrek antara lain:

a. Anggrek Bulan (Phalaenopsis)

Merupakan bunga yang pertama kali ditemukan di Maluku. Salah satu bunga nasional, merupakan anggrek monopodial, menyukai sedikit cahaya, dengan bentuk kelopak bunga yang lebar bewarna putih, daun berbentuk memanjang, akar putih berbentuk bulat memanjang. Dan anggrek bulan ini bunga yang awet saat berbunga.

b. Anggrek Larat (Dendrobium)

Merupakan anggrek yang berasal dari Maluku, bunga anggrek larat ini bewarna keunguan pucat hingga ungu tua, daun mahkota lebih pendek, tetapi lebih lebar daripada kelopaknya. Pangkalnya sempit dan ujungnya runcing. Tumbuh baik di daerah panas. Dan dijadikan bunga maskot di Provinsi Maluku.

\subsection{Gray Level Co-occurence Matrix (GLCM)}

GLCM adalah suatu matrik kookurensi yang elemenelemennya merupakan jumlah kemunculan piksel-piksel yang memiliki nilai tingkat keabuan tertentu, di mana pasangan piksel itu berada pada jarak (d) dan sudut tertentu (Ө)[11]. Orientasi sudut yang digunakan adalah yaitu sudut $0^{\circ}, 45^{\circ}, 90^{\circ}, 135^{\circ}, 180^{\circ}$ dst Sedangkan jarak antar piksel biasanya ditetapkan sebesar 1 piksel, atau 2 piksel [12]. Dalam penelitian ini menggunakan empat fitur ciri yaitu :

a. Energi

Energi menyatakan ukuran konsentrasi pasangan dengan intensitas keabuan tertentu pada matriks. Nilai energi (E) dapat dihitung dengan persamaan satu.

$$
E=\sum_{i, j}\left(p_{i, j}\right)^{2}
$$

Dengan :

$\mathrm{i}=$ tingkat keabuan baris $\mathrm{ke}-\mathrm{i}$

$\mathrm{j}=$ tingkat keabuan kolom $\mathrm{ke}-\mathrm{j}$

$\mathrm{p}_{\mathrm{i}, \mathrm{j}}=$ Peluang keabuan baris ke $-\mathrm{i}$, kolom ke $-\mathrm{j}$

\section{b. Entropi}

Entropi menunjukkan ketidakteraturan dari ukuran bentuk, jika nilai Entropi- nya besar untuk citra dengan transisi nilai derajat keabuan yang teratur, dan bernilai kecil jika struktur citra tidak teratur (bervariasi). Nilai Entropi (EN) dapat dihitung dengan persamaan nomor 2 .

$$
E N=\sum_{i, j} p_{i, j}\left(-\ln \left(p_{i, j}\right)\right)
$$

Dengan :

$\mathrm{p}_{\mathrm{i}, \mathrm{j}}=$ Peluang keabuan baris ke $-\mathrm{i}$, kolom $\mathrm{ke}-\mathrm{j}$

In $\mathrm{p}_{\mathrm{i}, \mathrm{j}}=$ Logaritma natural dari $\mathrm{p}_{\mathrm{i}, \mathrm{j}}$

\section{c. Kontras}

Kontras menyatakan perbedaan intensitas antara nilai tertinggi (terang) dan nilai terendah (gelap) dari sepasang piksel yang saling berdekatan. Nilai kontras (CON) dapat dihitung dengan persamaan nomor 3 .

$$
\text { CON }=\sum_{i, j} i-j^{2} p_{i, j}
$$

Dengan :

$\mathrm{i}=$ tingkat keabuan baris $\mathrm{ke}-\mathrm{i}$

$\mathrm{j}=$ tingkat keabuan kolom $\mathrm{ke}-\mathrm{j}$

$\mathrm{p}_{\mathrm{i}, \mathrm{j}}=$ Peluang keabuan baris ke $-\mathrm{i}$, kolom $\mathrm{ke}-\mathrm{j}$ 


\section{d. Homogenitas}

Homogenitas

kehomogenan

digunakan untuk mengukur homogenitas $(\mathrm{H})$ dapat dihitung dengan persamaan nomor 4

$$
H=\sum_{i, j} \frac{p_{i, j}}{1+|i-j|}
$$

Dengan :

$\mathrm{i}=$ tingkat keabuan baris $\mathrm{ke}-\mathrm{i}$

$\mathrm{j}=$ tingkat keabuan kolom $\mathrm{ke}-\mathrm{j}$

\subsection{Algoritma K-Nearst Neighbor}

K-Nearest Neighbor adalah pendekatan untuk mencari kasus dengan menghitung kedekatan antara kasus baru dan kasus lama, yaitu setiap contoh baru dapat diklasifikasikan oleh suara mayoritas dari $\mathrm{k}$ tetangga, di mana $\mathrm{k}$ adalah bilangan bulat positif, dan biasanya dengan jumlah kecil [13].

Klasifikasi terhadap objek berdasarkan data pembelajaran yang jaraknya paling dekat dengan objek tersebut. K-Nearest Neighbor merupakan metode klasifikasi instance-based, memilih satu objek latih yang memiliki sifat ketetanggaan (neighborhood) yang paling dekat. Sifat ketetanggaan ini didapatkan dari perhitungan nilai kemiripan ataupun ketidakmiripan. KNN menggunakan metode perhitungan nilai ketidakmiripan (Euclidian, Manhattan, Square Euclidian, dll). KNN akan memilih K-tetangga terdekat untuk menentukan hasil klasifikasi dengan melihat jumlah kemunculan dari kelas dalam K-tetangga yang terpilih. Kelas yang paling banyak munculah yang akan menjadi kelas hasil klasifikasi.

$$
D(a, b)=\sqrt{\sum_{k=1}^{d}\left(a_{k}-b_{k}\right)^{2}}
$$

dimana matriks $\mathrm{D}(\mathrm{a}, \mathrm{b})$ adalah jarak skalar dari kedua vektor a dan b dari matriks dengan ukuran d dimensi.

Pada fase training, algoritma ini hanya melakukan penyimpanan vektor-vektor fitur dan klasifikasi data training sample. Pada fase klasifikasi, fitur-fitur yang sama dihitung untuk testing data (yang klasifikasinya tidak diketahui). Jarak dari vektor baru yang ini terhadap seluruh vektor training sample dihitung dan sejumlah $\mathrm{k}$ buah yang paling dekat diambil. Titik yang baru klasifikasinya diprediksikan termasuk pada klasifikasi terbanyak dari titik-titik tersebut.

Langkah-Langkah Menghitung Metode K-NN adalah sebagai berikut:

1. Menentukan parameter $\mathrm{K}$ (jumlah tetangga paling dekat).

2. Menghitung kuadrat jarak euclid (query instance) masing-masing obyek terhadap data sampel (data baru) yang diberikan.

3. Kemudian mengurutkan objek-objek tersebut kedalam kelompok yang mempunyai jarak euclid terkecil.

4. Mengumpulkan kategori Y (Klasifikasi nearest neighbor)

5. Dengan menggunakan kategori nearest neighbor yang paling mayoritas maka dapat dipredisikan nilai query instance yang telah dihitung.

KNN memiliki beberapa kelebihan yaitu ketangguhan terhadap training data yang memiliki banyak noise dan efektif apabila training data-nya besar. Sedangkan, kelemahan KNN adalah KNN perlu menentukan nilai dari parameter $\mathrm{k}$ (jumlah dari tetangga terdekat), training berdasarkan jarak tidak jelas mengenai jenis jarak apa yang harus digunakan dan atribut mana yang harus digunakan untuk mendapatkan hasil terbaik, dan biaya komputasi cukup tinggi karena diperlukan perhitungan jarak dari tiap query instance pada keseluruhan training sample [18].

\section{METODOLOGI}

\subsection{Metodologi Peneltian}

Langkah-langkah identifikasi bunga anggrek pada penelitian ini dapat dilihat pada gambar 1 .

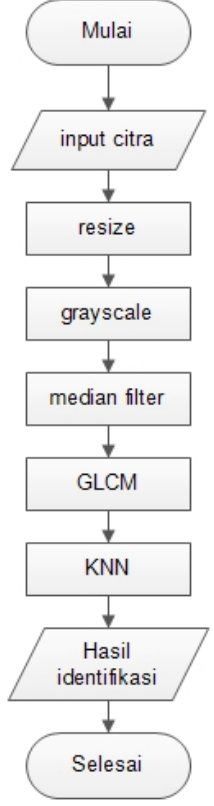

Gambar 1. Alur Proses Identifikasi

Proses awal yang perlu dilakukan adalah mengidentifikasi otomatis yang di awali dengan membuka image dan melakukan resize dan grayscale setelah itu di lakukan median / filter dengan tujuan mengurangi noise, setelah itu dilakukan proses ektrasi ciri GLCM untuk mengambil nilai energy, kontras, entropi, dan homogenitas dari citra untuk selanjutnya nilai tersebut digunakan sebagai keputusan menggunakan metode KNN.

\subsection{Perancangan Sistem}

Target pengguna dari perangkat lunak yang akan dibangun adalah seorang admin atau pemerhati anggrek dengan kebutuhan fungsi utama yaitu mengenali anggrekk secara otomatis, oleh sebab itu dapat diidentifikasi fungsionalitas dari perangkat lunak yang akan dibangun adalah seperti pada gambar 2 .

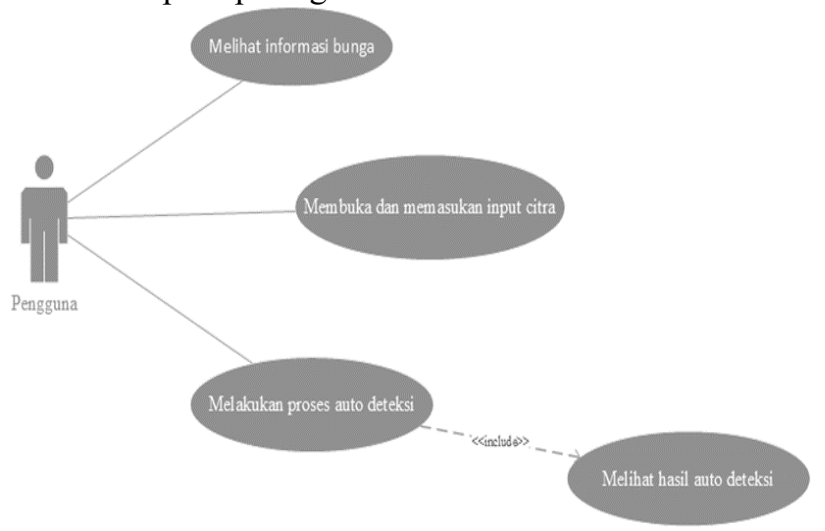

Gambar 2. Aktor Dan Fungsionalitas Sistem 


\subsection{Perancangan Intput}

Input dari aplikasi ini adalah sebuah file yang kita ambil atau kita pilih dari gallery album foto anggrek, rancangan user interface untuk melakukan proses tersebut dapat dilihat pada gambar 3 .

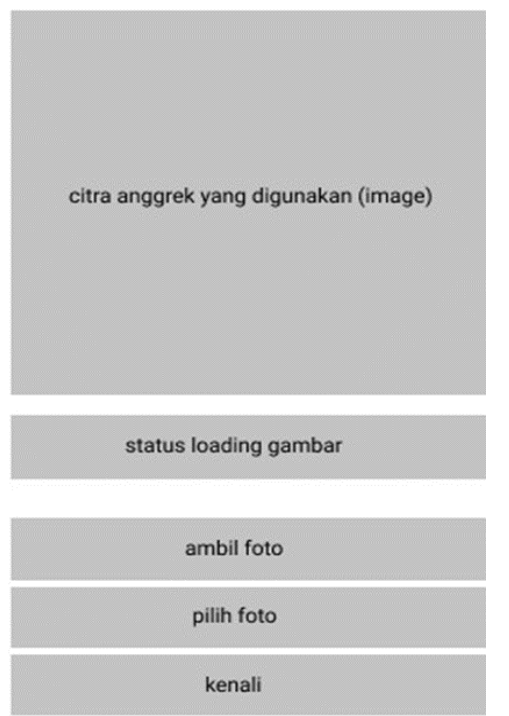

Gambar 3. Desain Tampilan Input Gambar

Menu ambil foto digunakan untuk mengambil foto secara langsung menggunakan kamera Handphone selanjutnya Citra Foto akan muncul pada bagian "Citra Anggrek yang digunakan (image). Menu pilih foto digunakan untuk memilih foto yang berada didalam galeri Handphone, dan Menu kenali yaitu untuk mengenali Gambar atau Citra Anggrek dan Bukan Anggrek.

\subsection{Perancangan Output}

Output dari aplikasi ini adalah sebuah hasil klasifikasi jenis bunga anggrek yang merupakan hasil dari Algoritma KNN dengan rancangan tampilan dari output sebagimana pada gambar 4 .

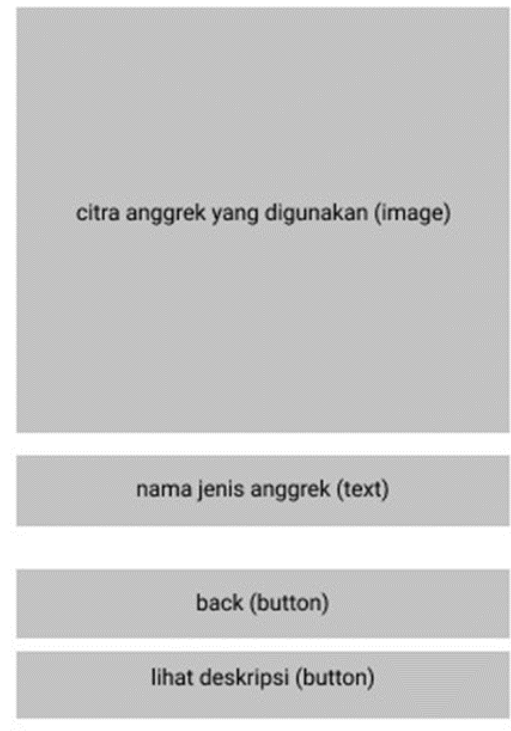

Gambar 4. Desain Tampilan Output

Bagian "citra anggrek yang digunakan (image)" menunjukan citra anggrek yang sebelumnya dipilih, selain menampilkan hasil citra disertakan juga informasi dari bunga anggrek tersebut.

\subsection{Alur Penggunaan Aplikasi}

Langkah pertama penggunaan aplikasi diawali dengan membuka atau mengambil foto yang ingin digunakan, selanjutnya untuk mengenali gambar tersebut pengguna dapat memilih tombol kenali, setelah itu hasil dari pengenalan ditampilkan pada halaman output pengguna dapat mengetahui deskripsi dari bunga dengan memilih tombol deskripsi yang akan membawa pengguna kealamat website Wikipedia yang berisi keterangan dari bunga tersebut. Alur penggunaan aplikasi dapat dilihat pada gambar 5.

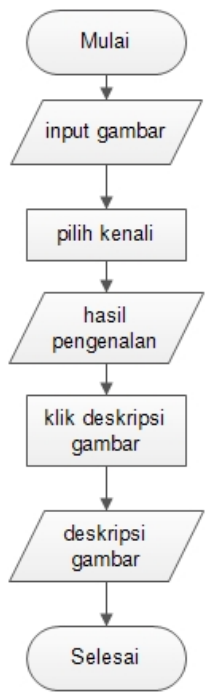

Gambar 5. Alur Penggunaan Aplikasi

\section{HASIL DAN ANALISIS}

\subsection{Realisasi Perancangan}

a. Proses ambil foto

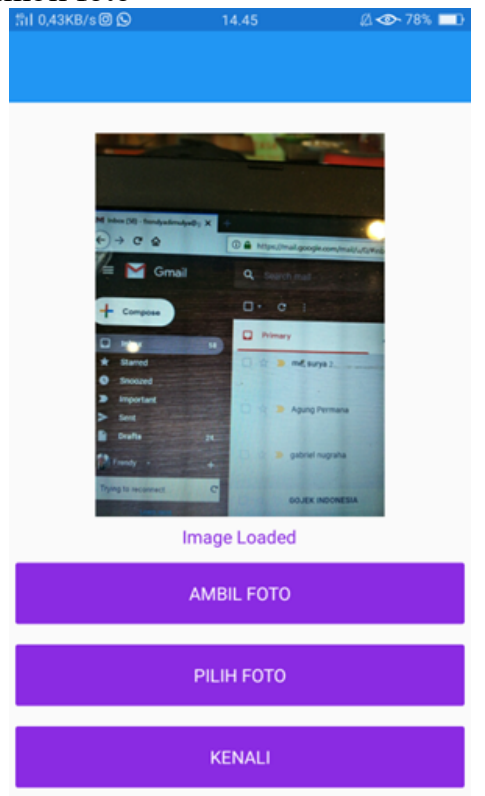

Gambar 6. Proses Ambil Gambar

Gambar 6 merupakan tampilan aplikasi untuk mengambil foto bunga anggrek yang akan dikenali atau diidentifikasi. 


\section{b. Proses Kenali}

Proses ini untuk melakukan identifikasi bunga anggrek. Pada proses ini meliputi proses ekstrasi ciri dan proses KNN. Gambar 7 (a) merupakan tampilkan aplikasi yang menyajikan nilai-nilai Energy, Entropy, Contras, dan Homogenitas dari citra bunga anggrek yang digunakan. Nilai-nilai tersebut murapakan hasil perhitungan dari metode GLCM. Sedangkan gambar 7 (b) merupakan tampilan aplikasi yang menyajikan informasi hasil identifikasi bunga anggrek.

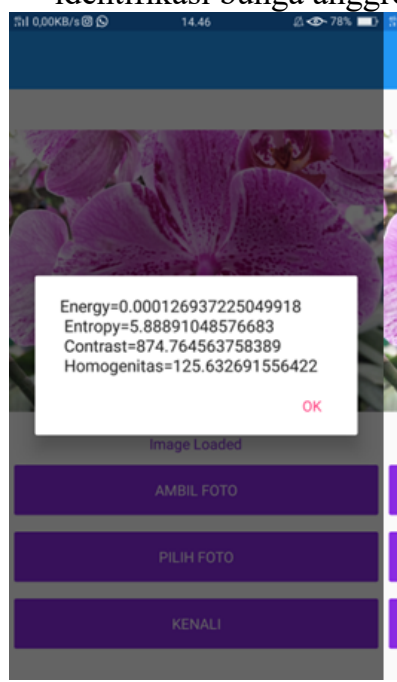

a.

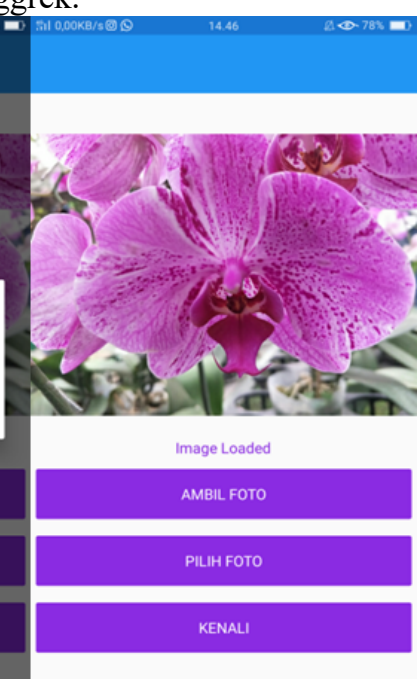

b.
Gambar 7.

(a) Tampilan Hasil Perhitungan Metode

(b) Tampilan Hasil Identifikasi Bunga

\section{c. Deskripsi}

Setelah citra bunga dapat dikenali atau diidentifikasi, pengguna juga dapat informasi tentang bunga anggrek yang telah dikenali. Pada bagian ini berfungsi untuk menambah wawasan tentang bunga anggrek untuk pengguna. Proses menampilkan deskripsi seperti pada gambar 8 .

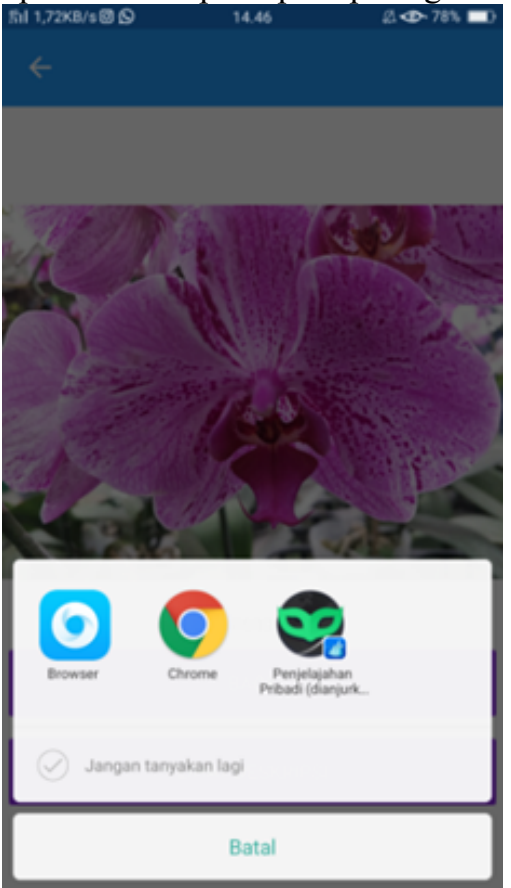

Gambar 8. Tampilan Program Deskripsi

\subsection{Pengujian Sistem}

Data yang digunakan sebagai data training pada aplikasi yang dibangun berjumlah 75 data dengan perincian 25 data bunga jenis phalaenopsis, 25 data jenis dendrobium, 25 data bukan anggrek. Data Testing berjumlah 15 dengan perincian 5 data bunga jenis phalaenopsis, 5 data jenis dendrobium, 5 data bukan anggrek.

a. Skenario 1

Pada skenario 1 Pengujian dilakukan dengan parameter K bernilai 1 . Rata - rata akurasi pada skenario 1 yaitu $80 \%$. Detail hasil pengujian dapat dilihat pada tabel 1 .

Tabel 1. Hasil Pengujian Skenario 1

\begin{tabular}{rlccc}
\hline No & Pengujian & B & S & Akurasi \\
\hline 1 & Dendrobium & 3 & 2 & $60 \%$ \\
2 & Phalaenopsis & 4 & 1 & $80 \%$ \\
3 & Bukan Anggrek & 5 & 0 & $100 \%$ \\
\hline
\end{tabular}

b. Skenario 2

Pada skenario 2 Pengujian dilakukan dengan parameter $\mathrm{K}$ bernilai 5. Hasil pengujian skenario 2 sama dengan skenario 1 yaitu rata-rata akurasi $80 \%$. Hasil pengujian dapat dilihat pada tabel 2 .

Tabel 2. Hasil Pengujian SKenario 2

\begin{tabular}{rlrrc}
\hline No & Pengujian & B & S & Akurasi \\
\hline 1 & Dendrobium & 3 & 2 & $60 \%$ \\
2 & Phalaenopsis & 4 & 1 & $80 \%$ \\
3 & Bukan Anggrek & 5 & 0 & $100 \%$ \\
\hline
\end{tabular}

c. Skenario 3

Pada skenario 3 Pengujian dilakukan dengan parameter K bernilai 9. Hasil pengujian dengan skenario 3 rata-rara akurasi $73 \%$, lebih rendah dari skenario 1 dan 2 . Tabel 3 merupakan detail hasil ujicoba skenario 3.

TABel 3. Hasil Pengujian SKenario 3

\begin{tabular}{rllll}
\hline No & Pengujian & B & S & Akurasi \\
\hline 1 & Dendrobium & 3 & 2 & $60 \%$ \\
2 & Phalaenopsis & 3 & 2 & $60 \%$ \\
3 & Bukan Anggrek & 5 & 0 & $100 \%$ \\
\hline
\end{tabular}

d. Skenario 4

Pada skenario 4 Pengujian dilakukan dengan parameter K bernilai 13. Rata - rata akurasi yang didapat pada skenario 4 yaitu $73 \%$, hasil ini sama dengan skenario 3. Detail hasil pengujian dapat dilihat pada tabel 4.

TABel 4. Hasil Pengujian SKenario 4

\begin{tabular}{rlccc}
\hline No & Pengujian & B & S & Akurasi \\
\hline 1 & Dendrobium & 3 & 2 & $60 \%$ \\
2 & Phalaenopsis & 3 & 2 & $60 \%$ \\
3 & Bukan Anggrek & 5 & 0 & $100 \%$ \\
\hline
\end{tabular}

Dari hasil pengujian seluruh skenario diapatkan akurasi maksimal adalah $80 \%$ dengan menggunakan nilai $\mathrm{K} 1$ dan 5 , sedangkan akurasi minimum $73 \%$ dengan menggunakan nilai K 9 dan 13. Rata-rata akurasi dari seluruh skenario yaitu $77 \%$ seperti pada tabel 5 . Semakin besar nilai K akurasi semakin kecil, sehingga nilai $\mathrm{K}$ berpengaruh pada akurasi. Untuk mendapat akurasi yang optimal disarankan menggunakan nilai $\mathrm{K} 1$. 
Tabel 5. Rekap Hasil Pengujian Seluruh SKenario

\begin{tabular}{clll}
\hline No & Pengujian & K & Akurasi \\
\hline 1 & Skenario 1 & 1 & $80 \%$ \\
2 & Skenario 2 & 5 & $80 \%$ \\
3 & Skenario 3 & 9 & $73 \%$ \\
4 & Skenario 4 & 13 & $73 \%$ \\
\hline \multicolumn{5}{c}{ Rata -rata } & & $77 \%$ \\
\hline
\end{tabular}

\section{KESIMPULAN}

Berdasarkan hasil pengujian dan analisa dari penelitian yang telah dilakukan dapat disimpulkan tingkat keberhasilan identifikasi Orchidaceae atau bunga anggrek mencapai $80 \%$ dengan rata-rata $77 \%$. Nilai K berpengaruh pada tingkat keberhasilan identifikasi, semakin besar nilai $\mathrm{K}$ akurasi semakin kecil.

\section{DAFTAR PUSTAKA}

[1] Sahertian, Dece Elisabeth. Sherly Meiske Seay, Keanekaragaman Jenis-jenis Anggrek di Hutan Lamasi Desa Murnaten Kecamatan Taniwel kabupaten Seram Bagian Barat Maluku, Jurnal Agrium, Vol.12 no. 1, 2015.

[2] Rikardus, Hari Prayogo dan Hafiz Ardian, Analisis Keanekaragaman Jenis Anggrek Alam (Orchidaceae) Pada Lindung Gunung Smahung Desa Saham Kecapatan Senggah Temila Kabupaten Landak, Jurnal Hutan Lestari Vol.5 No.2, 2017.

[3] M. Awanda, T. Rismawan., D. M. Midyanti, Aplikasi Klasifikasi Anggrek Berdasarkan warna dan bentuk bunga dengan metode LVQ berbasis web, Jurnal Coding Sistem Komputer Untan, vol 06 no. 02 hal 36-47.Pontianak, 2018

[4] Prastyaswara, Eka Cndyasa., Ni Kadek Ayu Wirdiani, Gusti Made Arya Sasmita. Analisis Perbandingan Metode Canny, Sobel dan HSV dalam Proses Identifikasi Bunga Anggrek Hibrida, Jurnal Merpati, vol 5 no 3, Universitas Udayana, 2017

[5] H. Wijayanto, Klasifikasi batik menggunakan metodee K-nearest Neighbour berdasarkan gray level Co-occurrance Matrices(GLCM), Teknik Informatika, Unidus, Semarang, 2015

[6] R.R Waliyansyah, K Adi, J.E. Suseno, Implementasi Metode Gray Level Co-occurrance Matrix dalam Identifikasi Jenis Daun Tengkawang, Jurnal JNTETI vol 7 no. 1,2018

[7] R. Widodo, Agus Wahyu Widodo, Arry Supriyanto, Pemanfaatan Ciri Gray Level Co-Occurrence Matrix (GLCM) Citra Buah Jeruk Keprok (Citrus reticulata Blanco) untuk Klasifikasi Mutu, Jurnal Pengembangan Teknologi Informasi dan Ilmu Komputer, Vol. 2, No. 11, November 2018

[8] D.P. Pamungkas, A.B. Setiawan, IMPLEMENTASI EKSTRASI FITUR DAN K-NEAREST NEIGHTBOR UNTUK IDENTIFIKASI WAJAH PERSONAL, Joutica vol 3 no 2 Lamongan : Unisla, 2018
[9] A. Rohman, Model Algoritma K-Nearest Neighbor (K-NN) Untuk Prediksi Kelulusan Mahasiswa, Jurnal Neo Teknika, Vol. 1 No.1 2015.

[10] F. Liantoni, dan H. Nugroho, "Klasifikasi Daun Herbal Menggunakan Naive Bayes Classifier dan KNearst Neighbor", Jurnal Simantec, Vol.5, No.1, 2015

[11] Noordama, Identifikasi Varietas Durio Zibethinus Berdasarkan Sebaran

Trikoma Daun Menggunakan GLCM dan KNN, Scientific Repository of Bogor Agricultural University, 2014

[12] Surya, R. A., Fadhil, A. \& Yudhana,Ekstraksi Ciri Metode Gray Level Co-Occurrence Matrix (GLCM) dan Filter Gabor Untuk Klasifikasi Citra Batik Pekalongan. Jurnal Informatika: Jurnal Pengembangan IT, Volume 022017

[13] H.S, Khamis, W.C, Kipruto, S. Kimani, Application of k-Nearest

Neighbor Classification in Medical Data Mining, International Journal of

Information and Communication Technology Research, Vol. 4, No, 4 ,2014

\section{BIODATA PENULIS}

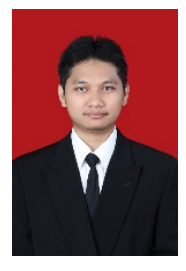

Danar Putra Pamungkas

Dosen Program Studi Teknik Informatika, Universitas Nusantara PGRI Kediri. Menyelesaikan S1 di Universitas Trunojoyo Madura dan S2 di STMIK Amikom Yogyakarta. 